\title{
Involuntary out-patient commitment: 2-year follow-up
}

\author{
Laura Castells-Aulet, ${ }^{1}$ Miguel Hernández-Viadel, ${ }^{1}$ Pedro Asensio-Pascual, ${ }^{1}$ Carlos Cañete-Nicolás, \\ Carmen Bellido-Rodríguez, ${ }^{2}$ Guillem Lera-Calatayud, ${ }^{3}$ Roman Calabuig-Crespo ${ }^{4}$
}

The Psychiatrist (2013), 37, 60-64, doi: 10.1192/pb.bp.112.040485

${ }^{1}$ Psychiatry Department, University Clinic Hospital, Valencia, Spain;

${ }^{2}$ Medical-Legal Institute of Valencia;

${ }^{3}$ Psychiatry Department, La Ribera

Hospital, Valencia; ${ }^{4}$ Psychiatry

Department, Doctor Peset University Hospital, Valencia

Correspondence to Laura

Castells-Aulet

(castells5@hotmail.com)

First received 18 Jun 2012, final

revision 18 Sep 2012, accepted 8 Nov 2012
Aims and method To evaluate the impact of involuntary out-patient commitment (OPC) in patients with severe mental disorder who use hospital services. This is a retrospective-observational study in a population of 91 patients under OPC. The psychiatric diagnosis, sociodemographic variables, who requested the court order and for what motive were studied. The study also looked at the use of the available health services (emergency room visits, admissions, average length of hospital stay) for the period beginning 2 years before and ending 2 years after the initiation of the OPC.

Results The number of emergency room visits, admissions and the length of hospitalisation diminished in the 2 years following the initiation of the OPC. In terms of diagnosis, the OPC has the most impact on individuals with schizophrenia and delusional disorder.

Clinical implications The OPC can be useful for certain patients with severe mental disorder, particularly individuals with schizophrenia and delusional disorder.

\section{Declaration of interest None.}

According to Swartz \& Swanson, ${ }^{1}$ involuntary out-patient commitment is a legal intervention designed to benefit persons with serious mental illness who need ongoing psychiatric care and support to prevent relapse, hospital readmissions, homelessness or incarceration, but have difficulty following through with community-based treatment. Out-patient commitment is a reality in many countries, among them Australia, New Zealand, the UK and the USA. ${ }^{2}$ In most parts of the USA, it is called involuntary out-patient commitment (OPC) or involuntary out-patient treatment and in New York State it is referred to as assisted out-patient treatment. In other countries, such as Canada or the UK, it is called community treatment order. In general, it does not include the power to enforce medication in the community, however, in a few countries such as Australia and New Zealand this authorisation is included. $^{2}$

Over the past few years OPC has caused a sharp debate at both a legal and a medical level. In medicine, there is the persistent controversy over whether it is effective at reducing the use of healthcare services and improving clinical results or the social functioning of the patient. In Spain, these differences are not only individual, but also cause disagreement among the different professional organisations. Whereas the Spanish Society of Psychiatrics (Sociedad Española de Psiquiatría) and the Spanish Society

†See also current practice (pp. 54-57) and commentary (pp. 58-59), this issue. of Legal Psychiatrics (Sociedad Española de Psiquiatría Legal) are in favour of $\mathrm{OPC}^{3}$ the Spanish Association of Neuropsychiatry (Asociación Española de Neuropsiquiatría) is against it. ${ }^{4}$ Box 1 shows the main arguments for and against. $^{5}$

\section{OPC in Spain}

In Spain, there is currently no specific legislation on OPC. There have been several attempts in parliament to legislate on this matter, but ultimately they have failed for lack of agreement. The OPC is applied on a discretionary basis as interpreted by each court in charge of incapacity and guardianship. In general, the courts use the law of involuntary admission, Article 763 of the Civil Procedure Act of 2000. Out-patient commitment is seen as a less restrictive alternative to hospitalisation.

The measure can be requested in court by a physician or the patient's family, with a favourable medical report. The initial duration of OPC is 18 months, and it is renewable for an additional 18 months. Stated in the court ruling are the mental health centre that attends to the patient and the treatment provided. The responsible clinician has to submit a report to the court every 3 months on the patient's progress and on the desirability of maintaining the court's measures. Although it may be requested directly from the mental health centre, in practice most OPC applications are made during admission, as a step preceding hospital discharge. 
Box 1 Principal arguments for and against out-patient commitment ${ }^{4}$

Arguments for

- The lack of recognition of the illness is a symptom in and of itself

- No one has demonstrated harmful side effects

- Compared to hospitalisation, it favours treatment in a less restrictive environment

- It makes the clinic responsible for the patient's evolution

- Helps avoid relapses and readmissions

- Improves the patient's quality of life

- Prioritises attention on the most severe cases. Gets services to the patients that most need it

- It is one of the inevitable consequences of deinstitutionalisation

- It is based on the social obligation to attend to and help the severely mentally ill, even if they do not desire it

- It can encourage the empowerment of community services

Arguments against

- A sufficient level of effectiveness remains undemonstrated

- It is an apparently easy solution for a more complex problem

- It is a terrible solution to an ill-posed problem

- It converts community into custodial treatment

- It destroys the therapeutic relationship

- It discriminates and increases a risk of stigmatisation of the patient and professionals

- It interferes with the right to refuse treatment

- It emphasises control more than assistance

- It devalues competent reasons for not accepting treatment

- It intimidates the patients, so they will come for treatment later than they should

- It has practical difficulties: the implementation of judicial and police complementary measures that are difficult to realise

- Being imposed, it reduces the possibility of negotiating with the patient

- It carries with it the risk of its use to exercise social control over persons with maladapted behaviour

- May cause hospitals to fill with non-compliant patients

There are doubts in Spanish legal circles about the legality of using OPC, given that there is no specific legislation regulating its use. Attorneys who specialise in the protection of persons with disabilities and tutorship ${ }^{6}$ consider it to be the Justice Ministry that initiates the request for an OPC, either by the modification of a patient's capacity or through the issuance of precautionary measures. Moreover, the Justice Ministry establish the minimum conditions before an OPC is to be issued.

The results that are available about the effectiveness of OPC are contradictory. Consequently, more information on this subject is needed. The aim of the present study was to determine the impact of OPC on the use of hospital services. If OPCs succeed at stabilising the medical condition of patients with severe mental illness and lower the number of relapses, their use will lead to lowering the number of emergency room visits, lowering the number of hospital admissions and shortening the length of hospital stay.

\section{Method}

This is a retrospective-observational study. The study population consisted of all the patients in the city of Valencia who have been under an OPC for at least 2 years at the initiation of the study (August 2009). Access to the population data was granted by the 13th Court of Valencia, which is in charge of internment processes and civil incapacitation. The study compared the use of healthcare services (emergency room visits, admissions and average length of hospitalisation) 2 years before and 2 years after the start of the OPC. The sociodemographic information recorded for each patient was: age, gender, civil status, residence, social and family support, work status, psychiatric diagnosis according to the DSM-IV-TR, ${ }^{7}$ comorbidities, number of psychiatric emergencies, number of hospital admissions and average length of hospital stay.

The data come from the records of hospitals in the city of Valencia. Emergencies include psychiatric emergencies only. Admissions include all admissions, voluntary and involuntary, registered in the psychiatry services during the study period.

\section{Ethical aspects}

The study design and execution meet the requirements of the Helsinki Declaration and the ethics laws related to the medical profession. The study is free from any institutional influence and has received no external financing.

\section{Results}

The cases and percentages presented correspond to the cases and valid percentages, excluding cases without information (missing cases).

- The study population comprises 91 patients with at least 2 years of OPC; $67 \%(n=61)$ were males and $33 \%(n=30)$ were females. The average age was 41 years; the youngest person was 22 and the oldest 71.

- Civil status ( $n=53$ valid cases): the majority of patients were single $(81 \%, n=43), 9 \%(n=5)$ were married and $9 \%$ $(n=5)$ were divorced or separated. 


\begin{tabular}{|c|c|}
\hline Diagnosis & $n(\%)$ \\
\hline $\begin{array}{l}\text { Axis I: first diagnosis } \\
\text { Schizophrenia } \\
\text { Delusional disorder } \\
\text { Bipolar disorder } \\
\text { Psychotic disorder NOS }\end{array}$ & $\begin{array}{c}63(69) \\
10(11) \\
9(10) \\
4(4)\end{array}$ \\
\hline $\begin{array}{l}\text { Axis I: second diagnosis } \\
\text { Substance misuse } \\
\text { No substance misuse } \\
\end{array}$ & $\begin{array}{l}29(32) \\
62(68) \\
\end{array}$ \\
\hline $\begin{array}{l}\text { Axis II } \\
\text { Personality disorder NOS } \\
\text { Antisocial personality disorder } \\
\text { Paranoid personality disorder } \\
\text { Dependent personality disorder } \\
\text { No personality disorder } \\
\end{array}$ & $\begin{array}{c}4(3) \\
3(2) \\
1(1) \\
1(1) \\
82(91)\end{array}$ \\
\hline Total sample & $91(100)$ \\
\hline
\end{tabular}

NOS, not otherwise specified.

- Place of residence $(n=78): 63 \%(n=49)$ lived with their family, $32 \%(n=25)$ lived alone and $5 \%(n=4)$ lived in medium- or long-term care centres.

- Family support $(n=79): 70 \%$ of patients $(n=55)$ had some family support, whereas $30 \%(n=24)$ did not.

- Occupational activity $(n=43)$ : the majority were on pensions $(65 \%, n=28) ; 28 \%(n=12)$ were unemployed or without a pension and only $5 \%(n=2)$ were actively employed; $2 \%(n=1)$ were temporarily unable to work.

The most frequent Axis I diagnosis was schizophrenia (Table 1), followed by delusional disorder and bipolar disorder.

Approximately a third of the patients had a secondary diagnosis of substance misuse or dependency. In one out of three patients diagnosed with schizophrenia $(n=21)$ or delusional disorder $(n=3)$ and in a half of those with bipolar disorder $(n=5)$, there was a secondary diagnosis of substance use disorder.

On Axis II, the diagnosis for four patients was personality disorder not otherwise specified (personality disorder NOS); for three patients, antisocial personality disorder; for one patient, paranoid personality disorder; and one other patient, dependent personality disorder (Table 1).

In the majority of cases $(78 \%, n=69)$, the OPC request came from the in-patient unit, during the patient's stay in hospital. In the rest of the cases, the request came from the mental health centre $(17 \%, n=15)$, the family $(3 \%, n=3)$ and from the addictive behaviour community unit $(1 \%, n=1)$. In three cases we did not find this information.

The most frequent motives for requesting an OPC were frequent relapses ( $57 \%$ of the cases, $n=50$ ), therapeutical non-adherence or no intention to take the treatment (23\%, $n=21)$ and because of the appearance of violent behaviour $(19 \%, n=17)$. In three cases we did not have this information.

Tables 2-4 show the use of hospital services (number of emergencies, number of hospital admissions and average length of hospital stay for those admitted) for the 1 and 2 years before and during the initiation of the OPC. The tables also present the results for the different diagnoses.

For the total sample $(n=91)$, there was a significant decrease in the three variables in the first and second year of OPC, compared with the same period before the initiation of the OPC. For diagnosis, only the individuals with schizophrenia and delusional disorder had a significant decrease in the number of admissions over the 2 years after the initiation of OPC. In those with bipolar disorder, the number of admissions also fell but not significantly. The average length of stay in hospital decreased considerably in all diagnoses, except for psychotic disorder NOS. The number of emergencies also fell over the 2 years of OPC but only significantly in the cases of schizophrenia (first year) and delusional disorder (second year).

\section{Discussion}

\section{Data on the effectiveness of OPC}

In a Cochrane systematic review in 2008, Kisely et $a l^{2}$ included the studies of Steadman et $a l^{8}$ and of Swartz \& Swanson, ${ }^{1}$ which consider there to be no significant differences in the use of healthcare services, social functioning or quality of life between OPC and standard treatment. Nevertheless, there was a lesser probability to be the victim of crime, violent or non-violent, in patients under an OPC.

In another review about international experiences, Churchill et $a l^{9}$ conclude that the efficacy measurements for OPC are inconsistent, and that there is no good evidence that it is effective at reducing the rate of hospital admittance.

In the first of two Australian studies, Ingram et $a l^{10}$ state that OPC may contribute to a better quality of life for the patient not only by cutting in half the occurrence of violent behaviour 1 year after the implementation of an OPC $(P<0.05)$, but also by significantly reducing the number of homeless patients $(P<0.05)$. In the second study, Segal \& Burgess $^{11}$ found that community treatment orders can prevent the use of hospital services in those patients who are at risk of prolonged psychiatric hospitalisation.

Swartz et $a l^{12}$ evaluated the effectiveness of the OPC programme in New York. They found that while under OPC there is a reduction in the number of admissions and in the length of hospital stay. Furthermore, there is a reduction in the probability of being arrested. This study also evaluated the perceptions of stigma, coercion and satisfaction with treatment during the OPC and found no changes. Once the OPC was terminated, there was a sustained improvement (lower rates of hospitalisation and medication nonadherence) in those patients who received intensive treatment or whose treatment lasted for more than 6 months. Another noteworthy result is that patients who underwent a combined treatment of OPC and assertive community treatment (ACT) had a lower risk for hospitalisation than did those who received only ACT.

\section{Study results}

In the present work, and in agreement with the medical literature (Steadman et $a l,{ }^{8}$ Swanson et al, ${ }^{13}$ Gilbert et $a l^{14}$ ), we have shown that OPC is applied with greater frequency to persons who are diagnosed with schizophrenia (69\%), those who have frequent relapses (57\%), show violent behaviour (19\%) or do not adhere to therapy (23\%). 
Table 2 Number of admissions according to primary diagnoses

\begin{tabular}{|c|c|c|c|c|c|c|c|}
\hline \multirow[b]{2}{*}{ Diagnosis } & \multirow[b]{2}{*}{$n$} & \multicolumn{6}{|c|}{ Admissions, mean $n^{a}$} \\
\hline & & $\begin{array}{c}1 \text { year before } \\
\text { OPC }\end{array}$ & $\begin{array}{l}1 \text { year during } \\
\text { OPC }\end{array}$ & $P$ & $\begin{array}{c}2 \text { years before } \\
\text { OPC }\end{array}$ & $\begin{array}{c}2 \text { years during } \\
\text { OPC }\end{array}$ & $P$ \\
\hline Schizophrenia & 63 & 1.3 & 0.4 & $<0.05$ & 1.6 & 0.6 & $<0.05$ \\
\hline Delusional disorder & 10 & 0.9 & 0.0 & $<0.05$ & 1.0 & 0.3 & $<0.05$ \\
\hline Bipolar disorder & 9 & 2.0 & 0.9 & 0.3 & 2.4 & 1.2 & 0.2 \\
\hline Schizoaffective disorder & 5 & 1.6 & 0.8 & $<0.05$ & 2.6 & 1.8 & 0.1 \\
\hline Psychotic disorder NOS & 4 & 1.0 & 0.0 & 0.1 & 1.5 & 0.0 & $<0.05$ \\
\hline Total sample & 91 & 1.3 & 0.4 & $<0.05$ & 1.7 & 0.7 & $<0.05$ \\
\hline
\end{tabular}

NOS, not otherwise specified; OPC, out-patient commitment.

a. Mean by $t$-test.

\begin{tabular}{|c|c|c|c|c|c|c|c|}
\hline \multirow[b]{2}{*}{ Diagnosis } & \multirow[b]{2}{*}{$n$} & \multicolumn{6}{|c|}{ Mean stay, $n^{a, b}$} \\
\hline & & $\begin{array}{c}1 \text { year before } \\
\text { OPC }\end{array}$ & $\begin{array}{l}1 \text { year during } \\
\text { OPC }\end{array}$ & $P$ & $\begin{array}{c}2 \text { years before } \\
\text { OPC }\end{array}$ & $\begin{array}{c}2 \text { years during } \\
\text { OPC }\end{array}$ & $P$ \\
\hline Schizophrenia & 63 & 22.4 & 4.5 & $<0.05$ & 21.5 & 7.4 & $<0.05$ \\
\hline Delusional disorder & 10 & 18.9 & 0.0 & $<0.05$ & 19.3 & 2.9 & $<0.05$ \\
\hline Bipolar disorder & 9 & 27.7 & 11.3 & $<0.05$ & 28.1 & 15.6 & $<0.05$ \\
\hline Schizoaffective disorder & 5 & 24.6 & 2.0 & $<0.05$ & 23.8 & 6.0 & $<0.05$ \\
\hline Psychotic disorder NOS & 4 & 11.0 & 0.0 & 0.1 & 10.0 & 0.0 & 0.1 \\
\hline Total sample & 91 & 22.2 & 4.3 & $<0.05$ & 21.4 & 7.1 & $<0.05$ \\
\hline
\end{tabular}

NOS, not otherwise specified; OPC, out-patient commitment.

a. $n=$ number of days.

b. Mean by $t$-test.

Table 4 Number of emergency visits according to primary diagnoses

\begin{tabular}{|c|c|c|c|c|c|c|c|}
\hline \multirow[b]{2}{*}{ Diagnosis } & \multirow[b]{2}{*}{$n$} & \multicolumn{6}{|c|}{ Emergency visits, mean ${ }^{a}$} \\
\hline & & $\begin{array}{c}1 \text { year before } \\
\text { OPC }\end{array}$ & $\begin{array}{l}1 \text { year during } \\
\text { OPC }\end{array}$ & $P$ & $\begin{array}{c}2 \text { years before } \\
\text { OPC }\end{array}$ & $\begin{array}{c}2 \text { years during } \\
\text { OPC }\end{array}$ & $P$ \\
\hline Schizophrenia & 63 & 1.4 & 0.7 & $<0.05$ & 1.8 & 1.4 & 0.2 \\
\hline Delusional disorder & 10 & 1.1 & 0.0 & 0.1 & 1.5 & 0.3 & $<0.05$ \\
\hline Bipolar disorder & 9 & 2.1 & 1.9 & 0.8 & 2.1 & 2.0 & 0.9 \\
\hline Schizoaffective disorder & 5 & 3.2 & 2.0 & 0.4 & 5.6 & 5.2 & 0.7 \\
\hline Psychotic disorder NOS & 4 & 2.2 & 0.0 & 0.2 & 3.5 & 0.0 & 0.3 \\
\hline Total sample & 91 & 1.6 & 0.8 & $<0.05$ & 2.1 & 1.5 & $<0.05$ \\
\hline
\end{tabular}

NOS, not otherwise specified; OPC, out-patient commitment.

a. Mean by $t$-test.

Given the most frequent sociodemographic variables, it is possible to determine the profile of a person put on an OPC: usually a male, 40 years of age on average, single, on a pension and who lives with his family. This remarkable consistency among users of OPC can help when considering which patients might benefit the most from this intervention.

In the present study, there was a significant decrease in the number of emergencies (from 2.1 to 1.5), admissions (from 1.7 to 0.7 ) and days hospitalised (from 21.4 to 7.1) in the 2 years following the initiation of the OPC. These results are similar to the results reported in other observational studies $^{12,15,16}$ which compared different periods pre/post intervention and found a decreased use of hospital services following the initiation of the OPC.

The greatest impact of OPC was observed for the average hospital stay, with a significant decrease for all diagnoses except for psychotic disorder NOS. The decrease in the number of admissions over the 2 years of OPC was significant only for people with schizophrenia and delusional disorder, which may suggest the type of patients who may benefit the most from this type of measure. The impact of OPC on emergencies for diagnosis is less clear, since decreasing the number of emergencies is significant only for delusional disorder.

Among other factors, the possible influence of OPC at the time of discharge and the development of enhanced community services, such as home treatment teams, could have influenced the results.

Despite the methodological weakness of observational studies, we consider the information offered by the present study to be of interest, given the long observation period. 
Several publications confirm that adherence to pharmacological treatment in disorders such as schizophrenia diminishes relapses and, consequently, the hospitalisations and the progressive deterioration that successive recurrences bring about. ${ }^{17-20}$ Therefore, the OPC may benefit a group of patients with a severe mental disorder, since it assures the continuation of treatment, avoids relapses and stabilises the illness.

The application of OPC should not be a generalised measure, but should be limited to those patients with a severe mental disorder, to those in whom a lack of therapeutic adherence will lead to a severe deterioration of the illness or the appearance of violent behaviour, things which would seriously compromise the patient's ability to live in the community.

It is possible that some patients could benefit from the use of intensive follow-up programmes such as ACT. Nevertheless, Swartz et $a l^{12}$ found that receiving ACT in combination with OPC reduces the risk of hospitalisation when compared with ACT alone. In conclusion, it is not a matter of one treatment replacing the other, but using them both in a complementary manner. Even though OPC may have advantages for some patients, the scientific evidence is still controversial. Therefore, new studies that offer more information about the effectiveness of OPC are required.

\section{About the authors}

Laura Castells-Aulet is a psychiatric registrar, Miguel Hernández-Viadel is a consultant psychiatrist, Pedro Asensio-Pascual is a consultant psychiatrist and Carlos Cañete-Nicolás is a consultant psychiatrist, all at the Psychiatry Department, University Clinic Hospital, Valencia, Spain. Carmen Bellido-Rodríguez is a forensic physician, Medical-Legal Institute of Valencia. Guillem Lera-Calatayud is a consultant psychiatrist, Psychiatry Department, La Ribera Hospital, Valencia. Roman Calabuig-Crespo is a consultant psychiatrist and chief of the Psychiatry Department, Doctor Peset University Hospital, Valencia.

\section{References}

1 Swartz MS, Swanson JW. Involuntary outpatient commitment, community treatment orders, and assisted outpatient treatment: what's in the data? Can J Psychiatry 2004; 49: 585-91.

2 Kisely S, Campbell LA, Preston N. Compulsory community and involuntary outpatient treatment for people with severe mental disorders. Cochrane Database Syst Rev 2005; 3: CD004408.

3 Spanish Society of Legal Psychiatry. Position of Spanish Society of Legal Psychiatry on Involuntary Outpatient Treatment. Available at: http:// www.psiquiatrialegal.org

4 Diaz Fernández E. Document S.N.A. regarding the proposal of regulation of the involuntary outpatient treatment for people with mental disorder. Span Assoc Neuropsychiatry Mag 2004; 24: 177-85.
5 Santander F. Tratamiento ambulatorio involuntaria: tal vez sí, pero [Community Treatment Orders (CTOs). Maybe, but . . .]. Cuad Psiquiatr Comunitaria 2006; 6: 47-54

6 Ganzenmüller Roig C. Conclusiones de las Jornadas de Fiscales Especializados en la Protección de las Personas con Discapacidad y Tutelas del 19 y 20 de Octubre de 2009. [Conclusions of the conference of prosecutors specialized in the protection of disability and guardianship of 19 and 20 October 2009]. Available at: http:// www.observatoriodeladiscapacidad. es/en/node/11231.

7 American Psychiatric Association. Diagnostic and Statistical Manual of Mental Disorders (4th edn, text revision) (DSM-IV-TR). APA, 2000.

8 Steadman HJ, Gounis K, Dennis D, Hopper K, Roche B, Swartz M, et al. Assessing the New York City involuntary outpatient commitment pilot program. Psychiatr Serv 2001; 52: 330-6.

9 Churchill R, Owen G, Singh S, Hotopf M. International Experiences of Using Community Treatment Orders. Department of Health, 2007 (http://www.dh.gov.uk/en/Publicationsandstatistics/Publications/ PublicationsPolicyAndGuidance/DH_072730).

10 Ingram G, Muirhead D, Harvey C. Effectiveness of community treatment orders for treatment of schizophrenia with oral or depot antipsychotic medication: changes in problem behaviours and social functioning. Aust N Z J Psychiatry 2009; 43: 1077-83.

11 Segal SP, Burgess P. Preventing psychiatric hospitalization and involuntary outpatient commitment. Soc Work Health Care 2009; 48: 232-42.

12 Swartz MS, Wilder CM, Swanson JW, Van Dorn RA, Clark Robbins PC, Steadman HJ, et al. Assessing outcomes for consumers in New York's assisted outpatient treatment program. Psychiatr Serv 2010; 61: 976-81.

13 Swanson JW, Swartz MS, Wagner HR, Burns BJ, Borum R, et al. Involuntary out-patient commitment and reduction of violent behaviour in persons with severe mental illness. Br J Psychiatry 2000; 176: 324-31.

14 Gilbert AR, Moser LL, Van Dorn RA, Swanson JW, Wilder CM, Robbins $P C$, et al. Reductions in arrest under assisted outpatient treatment in New York. Psychiatr Serv 2010; 61: 996-9.

15 Van Dorn RA, Swanson JW, Swartz MS, Wilder CM, Moser LL, Gilbert $A R$, et al. Continuing medication and hospitalization outcomes after assisted outpatient treatment in New York. Psychiatr Serv 2010; 61: 982-7.

16 Hernández-Viadel M, Cañete Nicolás C, Lera Calatayud G, Pérez Prieto JF, Roche Millan T. Tratamiento ambulatorio involuntario para personas con trastorno mental severo. Resultados de un estudio en la ciudad de Valencia [Involuntary outpatient treatment for people with severe mental disorders. Results of a study of Valencia city]. Psiquiatr Biol 2007; 14: 7-12.

17 Novick D, Haro JM, Suarez D, Perez V, Dittmann RW, Haddad PM Predictors and clinical consequences of non-adherence with antipsychotic medication in the outpatient treatment of schizophrenia. Psychiatry Res 2010; 176: 109-13.

18 Ascher-Synum H, Faries DE, Zhu B, Ernst FR, Swartz MS, Swanson JW Medication adherence and long-term functional outcomes in the treatment of schizophrenia in usual care. J Clin Psychiatry 2006; 67: 453-60.

19 Morken G, Widen JH, Grawe RW. Non-adherence to antipsychotic medication, relapse and rehospitalization in recent-onset schizophrenia. BMC Psychiatry 2008; 8: 32.

20 Ayuso-Guitiérrez JL, del Río Vega JM. Factors influencing relapse in the long-term course of schizophrenia. Schizophr Res 1997; 28: 199-206. 